\title{
The Interaction between Leaf Allelopathy and Symbiosis with Rhizobium of Ulex europaeus on Hawaii Island
}

\author{
Mika Hozawa * (D) and Eiji Nawata \\ Laboratory of Tropical Agriculture, Department of Agriculture, Kyoto University, Kitashirakawa Oiwakecho, \\ Sakyo-ku, Kyoto 606-8502, Japan; nawata@kais.kyoto-u.ac.jp \\ * Correspondence: hozawa.mika.82m@st.kyoto-u.ac.jp; Tel.: +81-757-536-353; Fax: +81-757-536-352
}

Received: 27 January 2020; Accepted: 6 February 2020; Published: 10 February 2020

check for updates

\begin{abstract}
The objective of this study was to assess the magnitudes of the leaf allelopathy of Ulex europaeus in two different habitats, and discuss the driver of the differences, including rhizobia. The magnitudes of leaf allelopathy of the samples collected in two different habitats were assessed by comparing the hypocotyl and radicle lengths of the lettuce seeds tested on the samples. One habitat was in and adjacent to an Acasia koa forest, while the other was more than $50 \mathrm{~m}$ away. A. koa is indigenous to Hawaii and known to have a close symbiotic relationship with Bradyrhizobium for nitrogen-fixing. Within the past three years, U. europaeus has newly invaded both sampling sites, whereas the $A$. koa forest has been there for several decades. The combined result of both hypocotyl and radicle lengths of the lettuce seeds tested on both sites by linear model and multicomparison analyses showed no significant difference. But the radicle lengths of the lettuce seeds tested on $U$. europaeus sampled in and adjacent to the $A$. koa forest were significantly longer than those of the samples more than $50 \mathrm{~m}$ away, as measured by $t$-test $(p=0.05)$. This result suggested that the magnitude of the leaf allelopathy of $U$. europaeus depended on the distance of the habitat from the A. koa forest.
\end{abstract}

Keywords: adaptation; Bradyrhizobium; invasive species; strategies

\section{Introduction}

Gorse, Ulex europaeus L., which belongs to Fabaceae, is a common native species in the Atlantic coast of Europe, e.g., in the United Kingdom, France, Spain, or Portugal [1]. It was introduced to European colonies in the 19th century as an ornament or hedgerow. In addition, the seeds were unintentionally carried in the fur of livestock, such as sheep, and spread worldwide. It is listed as one of the world's worst invasive alien species [2], and has invaded a wide range of habitats and climates, from temperate to tropical regions [3]. It has been causing serious economic and environmental problems in regions such as the American continent, the Hawaiian archipelago, Réunion, Australia, and New Zealand.

Plant legume species are known to have symbiotic relationships with rhizobia, i.e., soil-inhabiting bacteria in the root nodules [4]. Rhizobia fix nitrogen from the atmosphere for the growth of the host plant [5]. Although some previous studies have explained the benefits of the symbiosis of the bacteria, such as the metabolic products or oxygen generated during photosynthesis in the host plant promoting the growth and metabolism of the bacteria, the benefit of the bacteria has not been well elucidated [5]. U. europaeus, which belongs to the Fabaceae family, is known to have a symbiotic relationship with the rhizobia Bradyrhizobium [6], and the existence of Bradyrhizobium in soil is key to the successful invasion of $U$. europaeus [6]. 
In addition, allelopathy is known as another strategy used by invasive species to adapt to new environments $[7,8]$. Allelopathy is defined as any direct or indirect harmful or beneficial effect by one plant (including microorganisms) on another, through the production of chemical compounds that escape into the environment [9]. As the magnitude of the allelopathy of the leaf litter leachate of U. europaeus differs significantly according to the habitat [10], allelopathy has been suggested to be one of the adaptation strategies for $U$. europaeus to compete with other species. Bertin et al. [11] stated that the exudation of allelochemicals is multigenically regulated, but few studies have been conducted to elucidate the allelopathic effects in the rhizosphere on weedy species. It is also mentioned that the root exudates play a major role in the rhizosphere, but the effects from the leachate of the leaves cannot be denied. Considering these previous studies, we focused on the allelopathic effect of the leaf litter leachate of one of the weedy species, U. europaeus; specifically, on its activities in the rhizosphere.

In the southeast flank of Mauna Kea on Hawaii Island, U. europaeus bushes are often seen adjacent to Acacia koa forests. A. koa, indigenous to Hawaii and belonging to the Fabaceae family, is known to have a symbiotic relationship with Bradyrhizobium [6]. After the invasion of $U$. europaeus in the $A$. koa forest, the forest has been greatly diminished, and the lone $A$. koa tree left in the epicenter of $U$. europaeus bushes seems to have been weakened and disappeared in the future (personal observation). In brief, our hypothesis of the prioritized invasion sequence of $U$. europaeus in relation to $A$. koa is that it weakens the allelopathy against $A$. koa at the beginning to utilize the Bradyrhizobia on its root, and starts expelling A. koa by strong allelopathy after gaining Bradyrhizobia in the nodules that start fixing enough nitrogen for adaptation. Leary et al. [6] reported the genetic types of the Bradyrhizobium used by A. koa in Hakalau Forest on Hawaii Island, which is far from the U. europaeus-infested area, and those used by $U$. europaeus in the periphery and epicenter of the infested area. Two same box-PCR fingerprint types of Bradyrhizobium used by the two plant species were found, and one common type used by $A$. koa was also used by $U$. europaeus; this was the dominant type in $A$. koa. The chemical structure of nod factor receptors (NFRs) released from the rhizobium enables the rhizobium and the plant species to identify each other; the relationship mutually recognizes the rhizobium and the plant [5]. U. europaeus is thought to find the three box-PCR fingerprint types of Bradyrhizobium by the unique NFRs at the beginning of the invasion. If the dominant types of Bradyrhizobia used by U. europaeus are ubiquitous in the soil, $U$. europaeus does not need to rely on the three types of Bradyrhizobia, which are common in A. koa, to adapt to the new habitats on Hawaii Island. However, it is thought to be a natural process for U. euroapeus to start using the three box-PCR fingerprint types of Bradyrhizobium, which are known to be used by both $A$. koa and $U$. europaeus at the beginning of the invasion if there is the little dominant type of Bradyrhizobia available for U. europaeus. The aim of this study was to discuss our hypothesis by comparing the results of the assessment related to the magnitudinal difference in the leaf allelopathy according to the habitats.

\section{Methods and Materials}

\subsection{Plant Samples}

The leaf samples were obtained from seven mother trees on Hawaii Island at coordinates $19^{\circ} 41^{\prime} 13.6^{\prime \prime} \mathrm{N}$ and $155^{\circ} 26^{\prime} 44.2^{\prime \prime} \mathrm{W}$ (two mother trees were in and two mother trees were adjacent to the A. koa forest, altitude: $1888 \mathrm{~m}$ ) and $19^{\circ} 41^{\prime} 14.0^{\prime \prime} \mathrm{N}$ and $155^{\circ} 26^{\prime} 46.2^{\prime \prime} \mathrm{W}$ (three mother trees were more than $50 \mathrm{~m}$ away from the $A$. koa forest, altitude: 1945m) on March 8, 2018 (Figure 1). In the past three years, both places have been invaded by U. europaeus (personal observation) and partially covered by Kikuyu grass (Pennisetum clandestinum). The A. koa forest is several decades old, and grows on the substrate called "kipuka," similar to a sandbank made by the lava flows from Mauna Loa eruption in 1843 [12]. U. europaeus trees in and adjacent to the kipuka are sparsely distributed in $A$. koa forest. Each mother tree of $U$. europaeus away from the $A$. koa forest is isolated and is growing in the middle of the lava flow of the Mauna Loa eruption [12]. Leaves $5 \mathrm{~cm}$ from the tip of the branches were sampled and air-dried, and then kept in sealed plastic bags. 


\subsection{Experiments}

The sandwich method [13] was used to assess the magnitude of the allelopathy. Fifty mg of air-dried leaves were sandwiched by two layers $(5 \mathrm{~mL}$ each) of $0.5 \%$ agar (Wako Pure Chemical Industries, Ltd.) made with purified water in a plastic cup of $3 \mathrm{~cm}$ diameter with a lid; then, five lettuce seeds (cv. Great Lakes) were put on the top of the agar in each cup. Controls were five lettuce seeds put on only $0.5 \%$ agar. Lettuce (Lactuca sativa, Asteraceae) of cv. Great Lakes is universally used as a test plant because its seeds germinate rapidly and grow uniformly [13]. After incubating at a temperature of $25^{\circ} \mathrm{C}$ for $72 \mathrm{~h}$ in complete darkness, the length of the hypocotyls and radicles of the lettuce seeds were measured using a digital caliper. Before the experiment, the plastic cups and lids were disinfected by spraying $95 \%$ ethanol and air-drying. Ninety seeds (five seeds in each cup) were tested on the agar with leaves from two types of habitats, in and adjacent to the $A$. koa forest, and more than 50m away from the forest (Figure 1). The experiment was conducted from October 16 to 19, 2018, in the laboratory of Kyoto University, Kyoto, Japan.

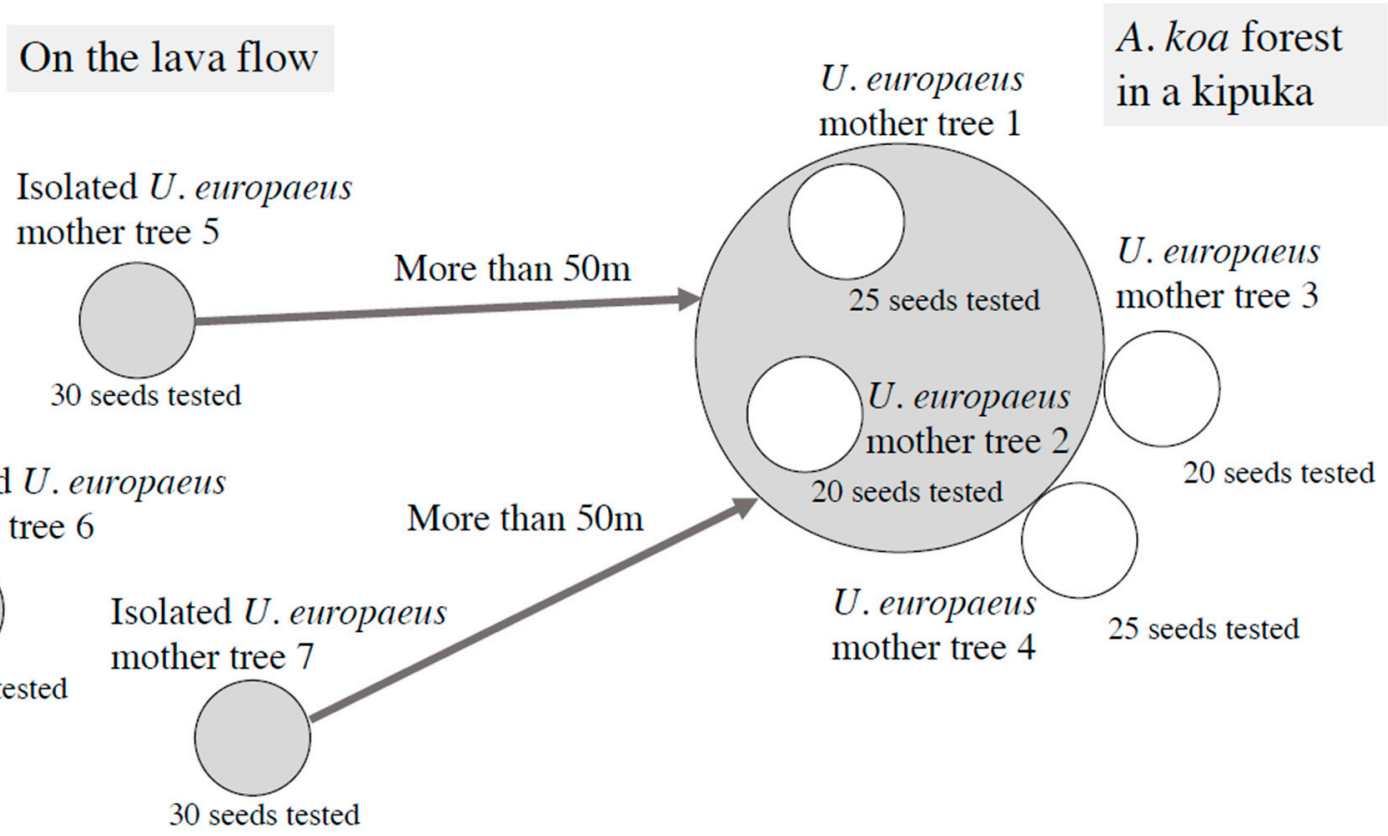

Figure 1. Details of the mother trees used for leaf sampling. Acasia koa has formed a forest in the kipuka (sandbank-like, old substrate made by the lava flow). Two mother trees each were in and adjacent to the A. koa forest. Three mother trees on the lava were isolated more than $50 \mathrm{~m}$ away from the A. koa forest. Lettuce seed numbers tested on the leaf samples are indicated below each mother tree.

\subsection{Statistical Analyses}

Paired $t$-tests compared the length of the hypocotyls and radicles of the lettuce seeds. The length of the hypocotyls and radicles of the lettuce seeds tested on the leaves sampled from the mother trees in the two types of habitats by the sandwich method were compared using linear model and multicomparison analyses.

Statistical analyses were performed using the $\mathrm{R}$ software, version 3.6.2 [14] and StatPlus (AnalystSoft Inc., Alexandria, VA, USA).

\section{Results and Discussion}

The radicles and hypocotyls of the lettuce seeds tested on the leaves from the two different habitats were both significantly shorter than those of the control (by $t$-test, $p<0.01, p<0.01$, respectively). By comparing the combined results of the hypocotyl and radicle lengths of the lettuce seeds tested on two different habitats, no significant difference was found (Figure 2 and Table 1). The hypocotyl 
lengths of the lettuce seeds tested on the leaves sampled in and adjacent to the $A$. koa forest and those tested on the leaves sampled more than $50 \mathrm{~m}$ away from the $A$. koa forest were not significantly different (Figure 3), but the radicle lengths of the lettuce seeds tested on the leaves sampled in and adjacent to the $A$. koa forest were significantly longer than those tested on the leaves sampled more than $50 \mathrm{~m}$ away $(p=0.05$, Figure 4$)$.

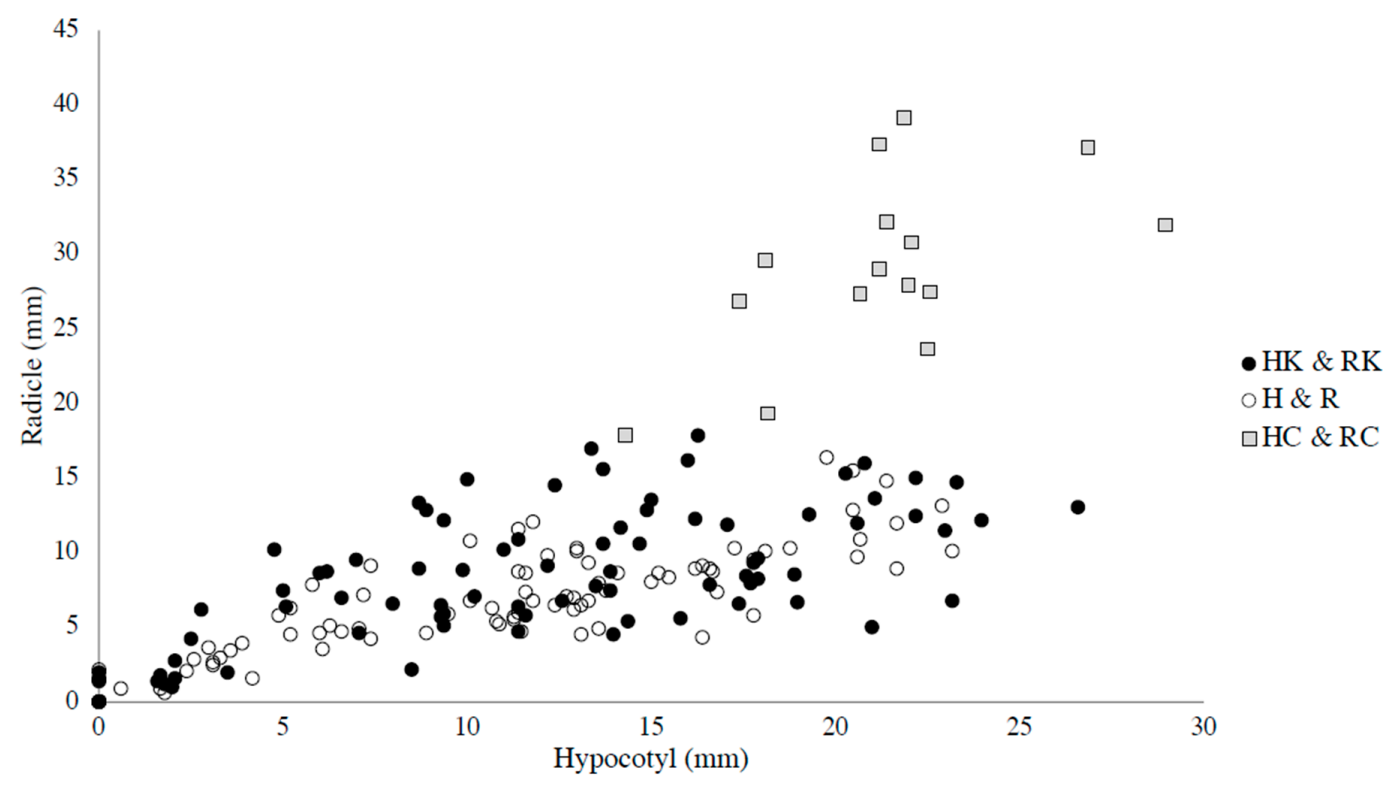

Figure 2. The length of the hypocotyls and radicles of the lettuce seeds tested on the leaves sampled from seven mother trees by the sandwich method were compared using linear model and multicomparison analysws. $\bullet$ : The hypocotyl and radicle lengths of the lettuce seeds tested on the leaves sampled in and adjacent to the $A$. koa forest. $\bigcirc$ : Hypocotyl and radicle lengths of the lettuce seeds tested on the leaves sampled more than $50 \mathrm{~m}$ away from the $A$. koa forest. $\square$ : Hypocotyl and radicle lengths of the lettuce seeds used as control.

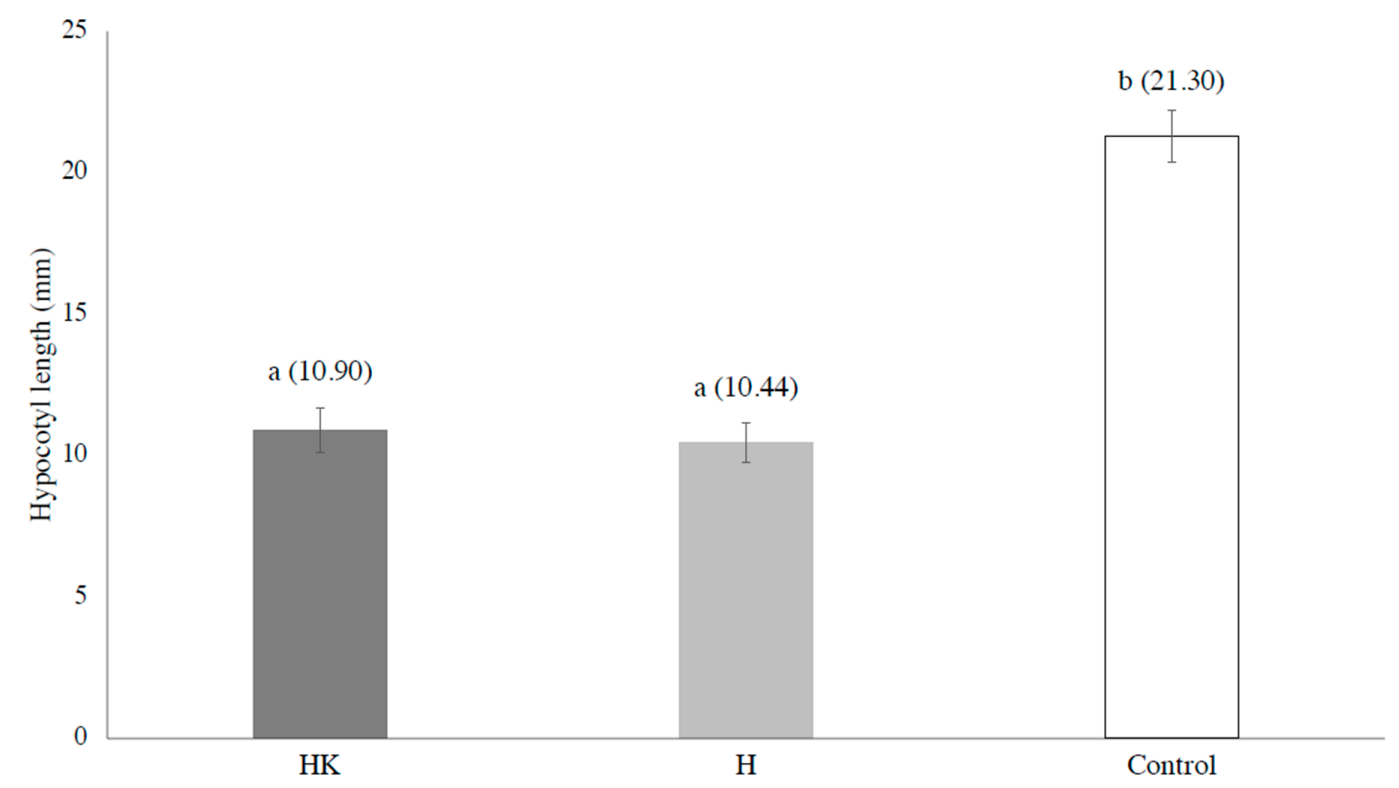

Figure 3. Hypocotyl lengths of lettuce seeds. HK: Hypocotyl lengths of the lettuce seeds tested on the leaves sampled in and adjacent to the $A$. koa forest. H: Hypocotyl lengths of the lettuce seeds tested on the leaves sampled more than $50 \mathrm{~m}$ away from the $A$. koa forest. C: Control. The bars represent standard error, and the different letters above bars indicate significant differences $(p<0.05)$. The numbers in the parenthesis are the mean values of the hypocotyls $(\mathrm{mm})$. 


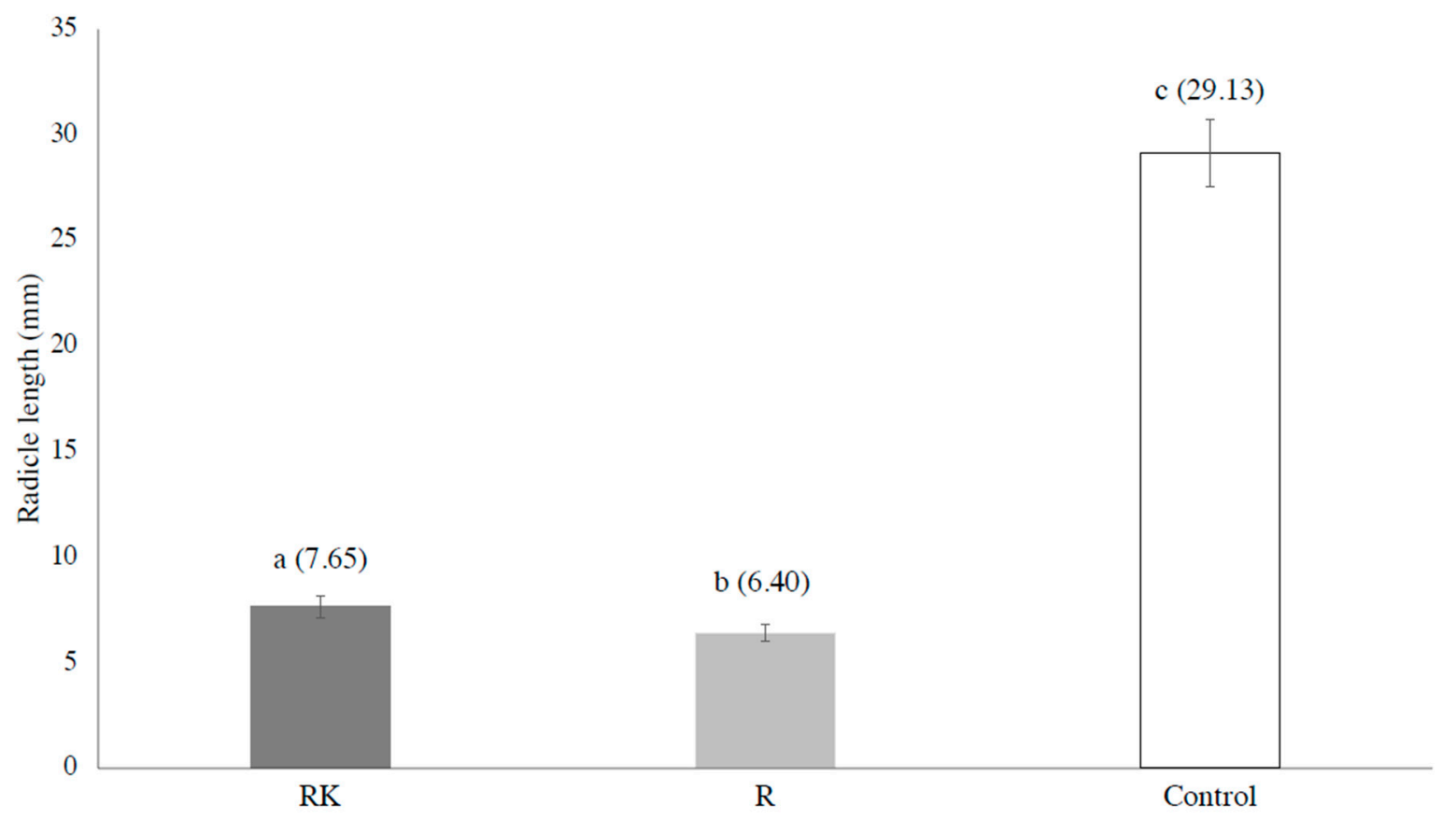

Figure 4. Radicle lengths of lettuce seeds. RK: Radicle of the lettuce seeds tested on the leaves sampled in and adjacent to the $A$. koa forest. R: Radicle of the lettuce seeds tested on the leaves sampled more than $50 \mathrm{~m}$ away from the $A$. koa forest. C: Control. The bars represent standard error, and the different letters above bars indicate significant differences $(p<0.05)$. The numbers in the parenthesis are the mean values of the hypocotyls ( $\mathrm{mm}$ ).

Table 1. The results of the multicomparison of the hypocotyl and radicle lengths of the lettuce seeds tested on the leaf samples. The lengths of the hypocotyls and radicles were significantly shorter than those of the control, but those of the samples tested in and adjacent to the Acasia koa forest, and those from more than $50 \mathrm{~m}$ away, were not significantly different.

\begin{tabular}{ccccc}
\hline & Estimate & Standard Error & t-Value & $p$-Value \\
\hline Close to Koa and control & -31.89 & 2.98 & -10.71 & $<0.001$ \\
Away from Koa and control & -33.59 & 2.98 & -11.28 & $<0.001$ \\
Close and away from Koa & -1.7 & 1.59 & -1.07 & 0.5 \\
\hline
\end{tabular}

The results suggest that the leaf allelopathy of $U$. europaeus against other species, maybe including A. koa, was strong. Focusing on the relationship of the leaf allelopathy and the distance from the A. koa forest, the magnitude of the leaf allelopathy was weaker in the leaves in and adjacent to the A. koa forest compared to those from the other sampling site, because the leaf litter leachate normally strongly enhances the growth of radicles [15]. As the key to successful adaptation and propagation of $U$. europaeus greatly depends on the existence of Bradyrhizobium [6], the allelopathy of the leaves might be adjusted when it is close to A. koa, which has a symbiotic relationship with Bradyrhizobium. Specifically, $U$. europaeus of the sampling sites, which are located in the new invasion area, is suggested to lack a common Bradyrhizobia type for both species, because it is still in the early stages of adaptation. However, A. koa seemed to be a competitive target for U. europaeus because the allelopathy of the leaves of $U$. europaeus grown in and adjacent to the $A$. koa forest was suggested to be stronger compared to the control (Figure 2 and Table 1). After obtaining enough bacteria which are common to $A$. koa and U. europaeus, U. europaeus may outcompete $A$. koa to obtain sunlight for photosynthesis. As mentioned, three common types of Bradhyrhizobia for both species have been reported [6]. U. europaeus may rely on the common symbiont of $A$. koa until it obtains its dominant type of Bradyrhizobia in the early stages of adaptation. Given that there was the abundant dominant type of Bradyrhizobium for U. europaeus except for in the $U$. europaeus-infested area in the study covering all genetic types of Bradyrhizobia 
of Hawaii Island, the hypothesis may be different. However, study to identify all the genetic types of Bradyrhozobia in the soil of Hawaii Island has not been done yet, and it could be even impossible. Furthermore, the magnitude of allelopathy of $U$. europaeus leaves of the mother trees, which have invaded areas in and adjacent to the $A$. koa forest in the past three years, should be tested and compared to the data of this study. If the magnitude of the leaf allelopathy of the leaves of the mother trees older than three years and grown in and adjacent to the $A$. koa forest is significantly stronger than that of the leaves sampled in the same habitat for this study, $U$. europaeus may have proceeded to the next sequence of adaptation in relation to $A$. koa. In addition, the interaction between other types of symbiotic nitrogen fixation, such as the genera of the bacterial group Frankia and Myrica faya, which are also seriously invasive in Hawaii, should be investigated in terms of invasion strategies to better understand our hypothesis in general.

\section{Conclusions}

To conclude, the results of this study show that the radicle lengths of the lettuce seeds tested on the leaf samples obtained from the mother trees in and adjacent to the $A$. koa forest were significantly shorter than those tested on the samples from more than $50 \mathrm{~m}$ away. This may be related to multigenic factors, including allelochemicals exuded from many parts of $U$. europaeus. However, the symbiotic relationship of $U$. europaeus with Bradyrhizobia in the new invasion sites is important because it causes a magnitudinal difference in the leaf allelopathy, depending on the habitats.

Author Contributions: M.H. and E.N. designed investigation and experiments, analyzed data, and wrote the manuscript. All authors have read and agreed to the published version of the manuscript.

Funding: This study was partly supported by a JSPS KAKENHI Grant (Grant No. 26257418).

Acknowledgments: We would like to thank J.B. Friday with the University of Hawaii at Manoa, Orlo Steele and Pamela Scheffler with Hawaii Community College for giving us advice, and staff of US Fish and Wildlife Service in Hakalau for supporting sampling.

Conflicts of Interest: The authors declare no conflicts of interest.

\section{References}

1. Holm, L.; Doll, J.; Holm, E.; Pancho, J.; Herberger, J. World Weeds: Natural Histories and Distribution.; Wiley-Blackwell. John Wiley and Sons: New York, NY, USA, 1997; p. 1129.

2. International Union for Conservation of Nature (IUCN) Invasive Species Specialist Group. Available online: http://www.issg.org/worst100_species.html (accessed on 24 November 2019).

3. Invasive Species Compendium (CABI) Ulex europaeus (gorse). Available online: https://www.cabi.org/ISC/ datasheet/55561 (accessed on 24 November 2019).

4. Weir, B.S.; Turner, S.J.; Silvester, W.B.; Park, D.C.; Young, J.M. Unexpectedly diverse Mesorhizobium strains and Rhizobium leguminosarum nodulate native legume genera of New Zealand, while introduced legume weeds are nodulated by Bradyrhizobium species. Appl. Environ. Microbiol. 2004, 70, 5980-5987. [CrossRef] [PubMed]

5. Gage, D.J. Infection and invasion of roots by symbiotic, nitrogen-fixing rhizobia during nodulation of temperate legumes. Microbiol Mol Biol. 2004, 68, 280-300. [CrossRef] [PubMed]

6. Leary, J.K.; Hue, N.V.; Singleton, P.W.; Borthakur, D. The major features of an infestation by the invasive weed legume gorse (Ulex europaeus) on volcanic soils in Hawaii. Biol. Fertil. Soils 2006, 42, 215-222. [CrossRef]

7. Bais, H.P.; Vepachedu, R.; Gilroy, S.; Callaway, R.M.; Vivanco, J.M. Allelopathy and Exotic Plant Invasion: From Molecules and Genes to Species Interactions. Science 2003, 301, 1377. [CrossRef] [PubMed]

8. Jarchow, M.E.; Cook, B.J. Allelopathy as a mechanism for the invasion of Typha angustifolia. Plant Ecol. 2009, 204, 113-124. [CrossRef]

9. Rice, E.L. Allelopathy, 2nd ed.; Academic Press: New York, NY, USA, 1984; 422p.

10. Hozawa, M.; Nawata, E. Variability and phenotypic plasticity of Ulex europaeus seeds in the Hawaiian Archipelago and California, USA: How do they support its invasiveness. In Proceeding of the 26th Asian-Pacific Weed Science Society Conference, Kyoto, Japan, 19-22 September 2017; p. 281. 
11. Bertin, C.; Yang, X.; Weston, L.A. The role of root exudates and allelochemicals in the rhizosphere. Plant Soils 2003, 256, 67-83. [CrossRef]

12. U.S. Geological Survey (USGS). Geological Map of the State of Hawaii. Available online: https://pubs.usgs. gov/of/2007/1089/ (accessed on 17 October 2019).

13. Fujii, Y.; Shibuya, T.; Nakatani, K.; Itani, T.; Hiradate, S.; Parvez, M. Assessment method for allelopathic effect from leaf litter leachates. Weed Biol. Manag. 2004, 4, 19-23. [CrossRef]

14. R Core Team. R: A Language and Environment for Statistical Computing; R. Foundation for Statistical Computing: Vienna, Austria, 2019; Available online: https://www.R-project.org (accessed on 10 November 2019).

15. Hilhorst, H.W.M.; Toorop, P.E. Review on dormancy, germinability and germination in crop and weed seeds. Adv. Agron. 1997, 61, 112-165.

(C) 2020 by the authors. Licensee MDPI, Basel, Switzerland. This article is an open access article distributed under the terms and conditions of the Creative Commons Attribution (CC BY) license (http://creativecommons.org/licenses/by/4.0/). 